Japan. J. Genetics Vol. 44, No. 1: 23-29 (1969)

\title{
DNA CONTENT PER NUCLEUS IN RELATION TO PHYLOGENY OF WHEAT AND ITS RELATIVES ${ }^{11}$
}

\author{
KOZO NISHIKAWA AND YOSHIHIKO FURUTA ${ }^{2}$ \\ Faculty of Agriculture, Gifu University, Gifu-ken 504
}

Received October 28, 1968

It is a well known fact that polyploidy plays an important role in the evolution of higher plants. The genus Triticum is divided into four groups according to morphological and cytogenetical features, that is, Einkorn group ( $n=7$, genome constitution A), Emmer group ( $n=14, \mathrm{AB})$, Timopheevi group $(n=14, \mathrm{AG})$ and Dinkel group $(n=21, \mathrm{ABD})$. After Kihara (1944) and McFadden and Sears $(1944,1946)$ the D genome of Dinkel group was contributed by Aegilops squarrosa $(n=14, \mathrm{D})$. On the other hand, Ae. speltoides has been considered to be the B genome donor to Emmer group (Sarkar and Stebbins 1956; Riley et al. 1958). However, the derivation of the G genome is not known yet.

Recently microspectrophotometry has been greatly improved and was applied to the cytological studies by many investigators. In Triticum, phylogenetical relationships have been discussed based on the DNA content per nucleus of related species since the beginning of the present decade.

Pai et al. (1961) reported that the DNA content per nucleus in common wheat was reduced by about one third of the sum of the DNA contents of its three analyzers. They thought that diminution of nuclear DNA was one of the diploidizing mechanisms which must have taken place in the evolutionary process of polyploid wheat. Upadhya and Swaminathan (1965) also recognized DNA diminution, but to a lesser extent than Pai et al. reported. Whereas, Rees (1963) and Rees and Walters (1965) could not detect the nuclear DNA diminution as reported by Pai et al. and reached the conclusion that polyploid wheat had a nuclear DNA content equal to the sum of DNA of its ancestors. Nishikawa and Furuta (1968) found no difference in DNA content per nucleus among 25 Japanese and U.S. varieties of common wheat.

As described above, there are discrepancies among the authors with respect to nuclear DNA content of wheat and its relatives. In order to throw new light upon this subject, the present investigation was carried out using artificially synthesized $6 \mathrm{x}$ wheat and its parental species in addition to diploid analyzers and common wheat.

\section{MATERIALS AND METHODS}

Species or strains used in the present study are listed in Table 1.

1) Contribution from the Laboratory of Genetics and Plant Breeding, Faculty of Agriculture, Gifu University, No. 38. The work has been supported in part by a grant from the Japan Society for the Promotion of Science as part of the Japan-U.S. Cooperative Science Program.

2) Present address: Laboratory of Genetics, Faculty of Agriculture, Kyoto University, Kyoto. 
Table 1. Species of Triticum, its relatives and synthesized $6 \mathrm{x}$ wheat used in the present study

\begin{tabular}{|c|c|c|}
\hline Species & $2 \mathrm{n}$ & Genome \\
\hline T. boeoticum BoIss. & 14 & AA \\
\hline T. monococcum L. var. vulgare KöRN. (Early) & 14 & AA \\
\hline Ae. speltoides TAUSCH & 14 & SS \\
\hline Ae. squarrosa L. var. typica ZHUk. No. 2 & 14 & $\mathrm{DD}$ \\
\hline ssp. strangulata & 14 & $\mathrm{DD}$ \\
\hline T. dicoccoides KÖRN. var. spontaneo-nigrum FLAKSB. & 28 & $\mathrm{AABB}$ \\
\hline T. dicoccum SchüBL. cultivar Vernal & 28 & $\mathrm{AABB}$ \\
\hline $\begin{array}{l}\text { T. aestivum (L.) HAYEK. ssp. vulgare (VILL.) MK } \\
\text { cultivar Chinese Spring }\end{array}$ & 42 & AABBDD \\
\hline $\begin{array}{l}\text { ssp. spelta (L.) THELL. } \\
\text { var. duhamelianum KöRN. }\end{array}$ & 42 & $\mathrm{AABBDD}$ \\
\hline $\begin{array}{c}\text { ssp. macha (DEK. et MEN.) MK } \\
\text { var. subletschchumicum }\end{array}$ & 42 & AABBDD \\
\hline $\begin{array}{l}\text { ABD No. 1: amphidiploid derived from } T . \text { dicoccoides } \\
\text { spontaneo-nigrum } \times \text { Ae. squarrosa var. typica } 2\end{array}$ & 42 & AABBDD \\
\hline $\begin{array}{l}\text { ABD No. 13: amphidiploid derived from } T \text {. dicoccum } \\
\text { (Vernal) } \times \text { Ae. squarrosa ssp. strangulata }\end{array}$ & 42 & AABBDD \\
\hline
\end{tabular}

Pollen tetrads are extreməly suitable for microspectrophotometry because they provide a large number of synchronized cells which can be easily squeezed out from the anther onto cover slips $(24 \times 32 \mathrm{~mm})$ and contain spherical nuclei with homogeneously distributed chromatin. The young anthers with pollen tetrads were fixed with aceticalcohol (1:3) for three days, soaked in $95 \%$ ethanol for three hours and stored in $75 \%$ ethanol in a refrigerator.

Cover slips on which pollen tetrads had been smeared were immersed in cold $\mathrm{N}-\mathrm{HCl}$ for 5 minutes, then hydrolyzed with $\mathrm{N}-\mathrm{HCl}$ at $60^{\circ} \mathrm{C}$ for five minutes and stained with Schiff's reagent according to Sibatani and Naora (1952). After washing in three changes of $\mathrm{SO}_{2}$ water, 15 minutes in each, permanent preparations were made by the routine method.

Measurement of DNA content per nucleus was exclusively made by the two wave length method (500 and $570 \mathrm{~m} \mu$ ), using Olympus microspectrophotometer (MSP A-IV), and the relative DNA value in arbitrary units was read from Mendelsohn's table (Mendelsohn 1958). Measurement was carried out in three replications; ten nuclei were selected for measurement for each species (or variety) per replication.

In order to minimize the errors, the two species (or varieties) that were compared were, if possible, smeared on the same cover slip, or a common standard species (or variety) was smeared side by side with the species (or variety) to be compared on every cover slip.

\section{RESULTS}

1. DNA content per nucleus in diploid analyzers

The variance analysis of DNA content per nucleus in three analyzers is given in 
Táble 2. Variance analysis and test of significance of mean DNA content per nucleus in three analyzers of wheat

(a) Variance analysis

\begin{tabular}{lrrc}
\hline Source & DF & SS & MS \\
\hline species & 4 & 487347 & $121837^{* *}$ \\
replicates & 10 & 69507 & $6951^{*}$ \\
error & 135 & 321559 & 2382 \\
\hline
\end{tabular}

(b) Test of significance

\begin{tabular}{lcccccc}
\hline \multicolumn{1}{c}{ Species } & Genome & Mean & -558 & -584 & -673 & -688 \\
\hline T. monococcum & $\mathrm{A}$ & 695 & $137^{*}$ & $111^{*}$ & 22 & 7 \\
$T$. boeoticum & $\mathrm{A}$ & 688 & $130^{*}$ & $104^{*}$ & 15 & \\
Ae. speltoides & $\mathrm{S}(\mathrm{B})$ & 673 & $115^{*}$ & $89^{*}$ & & \\
Ae. squarrosa & & & & & & \\
$\quad$ strangulata & $\mathrm{D}$ & 584 & $26^{*}$ & & & \\
typica No. 2 & $\mathrm{D}$ & 558 & & & & \\
\hline
\end{tabular}

* Significant at $5 \%$ level, ** Significant at $1 \%$ level

Table 3. DNA content per nucleus in common wheat (Chinese Spring), two strains of artificially synthesized $6 \mathrm{x}$ wheat and their parents

\begin{tabular}{lrlll}
\hline \multicolumn{2}{c}{ Series No. 1} & & \multicolumn{2}{c}{ Series No. 13 } \\
\cline { 5 - 5 } \multicolumn{1}{c}{ Species } & Mean $\pm \mathrm{SD}$ & & \multicolumn{1}{c}{ Species } & Mean $\pm \mathrm{SD}$ \\
\hline T. aestivum & $243.8 \pm 18.1$ & & T. aestivum & $613.7 \pm 54.1$ \\
ABD No. 1 & $209.8 \pm 19.2$ & & ABD No. 13 & $618.7 \pm 39.7$ \\
T. dicoccoides & $142.1 \pm 13.9$ & & T. dicoccum & $420.6 \pm 21.2$ \\
Ae. squarrosa typica & $71.4 \pm 4.3$ & & Ae. squarrosa strangulata & $175.7 \pm 13.0$ \\
\hline
\end{tabular}

Table 2. The significant difference between replications may be due to differences between the separately treated slides as to the color enhancement of Feulgen staining.

No difference was found not only between two species of the Einkorn group but also between Einkorn and Ae. speltoides. Whereas, DNA content of Ae. squarrosa (D genome analyzer) was evidently lower than that of the $\mathrm{A}$ and $\mathrm{B}$ genome analyzers. Moreover, it should be noticed that Ae. squarrosa ssp. strangulata contains a significantly higher amount of nuclear DNA than var. typica of the same species although this difference is not very large.

2. DNA content per nucleus in common wheat, artificially synthesized $6 x$ wheat and its parents

Table 3 represents the mean values of nuclear DNA and standard deviations in common wheat, two strains of artificially synthesized $6 \mathrm{x}$ wheat and their parents. The direct comparison should not be made between series No. 1 and series No. 13, because these two series of experiments were carried out separately.

If an additive relationship of nuclear DNA content is assumed between a given amphidiploid and its parental species, the expected DNA value would be 213.5 for ABD No. 1 and 596.3 for ABD No. 13, respectively. The observed values, 209.8 for the for- 
Table 4. Variance analysis of DNA content per nucleus of common wheat (Chinese Spring) and $\mathrm{ABD}$ No. 1

\begin{tabular}{lrrr} 
Source & DF & SS & MS \\
\hline Strains $(\mathrm{S})$ & 1 & 17304 & 17304 \\
Replicates $(\mathrm{R})$ & 2 & 261943 & 130972 \\
S $\times \mathrm{R}$ & 2 & 10251 & 5126 \\
Error & 54 & 114084 & 2113 \\
\hline
\end{tabular}

Table 5. Variance analysis of DNA content per nucleus in three subspecies of common wheat

\begin{tabular}{lrrrrr}
\multirow{2}{*}{ Source } & \multicolumn{2}{c}{ spelta-vulgare } & & \multicolumn{2}{c}{ spelta-macha } \\
\cline { 2 - 3 } & DF & MS & & DF & MS \\
\hline Subspecies $(\mathrm{S})$ & 1 & 11055 & & 1 & 2100 \\
Replicates $(\mathrm{R})$ & 1 & 130530 & & 2 & 38181 \\
S $\times \mathrm{R}$ & 1 & 11427 & & 2 & 23474 \\
Error & 36 & 3008 & & 54 & 3903 \\
\hline
\end{tabular}

mer and 618.7 for the latter are closely near to the expectation, strongly supporting the additive relationship. The comparison of DNA content between common wheat and recently synthesized $6 \mathrm{x}$ wheat would be most critical in deciding whether diminution of nuclear DNA had taken place or not in the evolutionary process of polyploid wheat species. DNA content per nucleus in ABD No. 13 is extremely close to that of a variety of common wheat, Chinese Spring, but that of ABD No. 1 is rather lowor than in Chinese Spring. However, the experiment in series No. 1 did not allow a direct comparison between ABD No. 1 and Chinese Spring, because the Emmer parent of ABD No. 1, T. dicoccoides was used as a standard species.

For direct comparison between ABD No. 1 and Chinese Spring, another series of experiments was carried out using the preparations in which pollen tetrads of ABD No. 1 and Chinese Spring were smeared side by side. The result (Table 4) was that Chinese Spring had higher amount of DNA than ABD No. 1, but the difference was not statistically significant.

\section{DNA content per nucleus in Dinkel wheat}

Variance analysis, the mean DNA contents and their standard deviations in three subspecies of Dinkel group are given in Table 5. The comparisons between ssp. spelta and ssp. vulgare (Chinese Spring) as well as between ssp. spelta and ssp. macha indicate that there was no significant difference among these three subspecies in relation to DNA content per nucleus.

\section{DISCUSSION}

Investigators who studied nuclear DNA amount in wheat and its relatives agree that diploid species differ in their DNA content depending upon the genomes they carry. 
Table 6. DNA content per nucleus in wheat and its relatives reported in the previous and present papers

\begin{tabular}{|c|c|c|c|c|c|c|c|}
\hline Species & Genome & $\begin{array}{l}\text { Pai } \\
\text { et al. }\end{array}$ & Rees & $\begin{array}{l}\text { Upadhya } \\
\text { et al. }\end{array}$ & $\begin{array}{l}\text { Rees and } \\
\text { Walters }\end{array}$ & \multicolumn{2}{|c|}{$\begin{array}{c}\text { Present } \\
\text { data }\end{array}$} \\
\hline$T$. monococcum & $\mathrm{A}$ & 1.07 & 1.30 & 1.09 & 1.31 & 1.22 & \\
\hline$T$. boeoticum & $\mathrm{A}$ & - & - & 1.11 & 1.36 & 1.20 & \\
\hline Ae. speltoides & $\mathrm{S}$ & 1.25 & 1.08 & 1.07 & 1.14 & 1.18 & \\
\hline Ae. squarrosa & $\mathrm{D}$ & 1.00 & 1.00 & 1.00 & 1.00 & $1.00 *$ & $1.00 * *$ \\
\hline$T$. dicoccoides & $\mathrm{AB}$ & - & - & 2.12 & 2.40 & 1.99 & - \\
\hline$T$. dicoccum & $\mathrm{AB}$ & 1.55 & - & 2.17 & 2.36 & - & 2.39 \\
\hline$T$. durum & $\mathrm{AB}$ & - & 2.25 & 2.37 & 2.37 & - & - \\
\hline T. aestivum & $\mathrm{ABD}$ & 2.06 & 3.29 & 2.92 & 3.40 & 3.41 & 3.49 \\
\hline ABD No. 1 & $\mathrm{ABD}$ & - & - & - & - & 2.94 & - \\
\hline ABD No. 13 & $\mathrm{ABD}$ & - & - & - & - & - & 3.52 \\
\hline
\end{tabular}

* Series No. 1, ** Series No. 13, (see Table 3)

The results of previous workers are summarized along with those of the present study in Table 6. Among the three genomes of wheat, genome D contains the lowest DNA, while $\mathrm{A}$ has the highest and $\mathrm{B}$ (or S) a little lower content than A, but not significantly different between the last two.

The present genomes of wheat and its relatives must have evolved from a common primitive genome through the accumulation of structural changes of chromosomes. Some of chromosome aberrations must have been accompanied by increase or decrease of chromatin in the course of genome differentiation. This might have resulted in various amounts of DNA specific for the genome concerned. A variable amount of nuclear DNA in diploid species was also reported in some genera other than Triticum. Rees and Jones (1967) presented evidence that in Lolium the evolution of diploid species was associated with variation of nuclear DNA content, namely, the DNA content of three inbreeding species was about 35\% larger than that of three outbreeding species tested. Rothfels et al. (1966), in the study on chromosome size and DNA content in species of Anemone and related genera, found considerable differences between genera but small within a genus. Southern (1967) studied the species relationship in Tulipa, and reported that in relation to DNA content per nucleus a continuous variation in diploid species was detected.

The DNA ratio in Einkorn (diploid), Emmer (tetraploid) and Dinkel (hexaploid) wheat is not 1:2:3; Bhaskaran and Swaminathan (1960) gave the ratio of $1: 1.5: 2.0$, Upadhya and Swaminathan (1963) 1:1.9:2.8, Rees (1963) $1: 1.7: 2.5$, Rees and Walters (1965) 1:1.8:2.5 and the present result was $1: 2.0: 2.8$. This can be easily explained by the difference in DNA content among the three wheat genomes. As is evident from Table 6, the result of Pai et al. is unique in that $T$. dicoccum has a much lower DNA content than the sum of the DNA contents of T. monococcum and Ae. speltoides, and that for T. aestivum is also lower than the sum of those for T. dicoccum and Ae. squarrosa. They explained these results by assuming that polyploid wheat diminished its nuclear DNA in the course of evolution and emphasized the importance of DNA diminution as a mechanism of functional diploidization. Upadhya and Swaminathan (1963) recognized the diminution of 
nuclear DNA in polyploid wheat, but to a lesser extent. However, Rees (1963) and Rees and Walters (1965) obtained no evidence that DNA amount appreciably diminished in polyploid wheat. They found that species or varieties with the same genome constitution have approximately the same amounts of nuclear DNA, and suggested the possibility that phylogenetical relationship can be traced by analyzing the DNA amount in related species.

The present investigation confirmed that DNA content per nucleus of a cultivated variety of common wheat is approximately equal to that of the two ABD strains of recently synthesized $6 \mathrm{x}$ wheat, especially No. 13. Moreover, there was no DNA difference among three subspecies of $T$. aestivum (Dinkel group). Those may suggest that the DNA content per nucleus of common wheat did not appreciably change since its origin several thousand years ago. The situation seems likely to be the same with Emmer wheat. Nishikawa and Furuta (1968) reported that they found no difference in DNA content per nucleus among 25 Japanese and U.S. varieties of common wheat. In addition, among species and varieties of Emmer wheat no differences were detected (Nishikawa and Sawai, unpublished). Taking these results into consideration, it may be concluded that the amount of DNA has been appreciably stable in polyploid wheat. In genus Oryza, Katayama (1967) reported that there could not be found any significant DNA differences among species with the same genome constitution. Though statistical analysis did not prove a significant difference between ABD No. 1 and ABD No. 13, the latter should be expected to contain a higher DNA amount than the former, because Emmer parents of ABD No. 1 and ABD No. 13 contain equal amounts of DNA and the $D$ genome parent of the latter has a higher DNA content than that of the former. Further investigations will be presented elsewhere.

Finally, according to Rees and Walters (1965) the G genome analyzer, if it exists, must have a lower DNA content than the B analyzer. Thus, it is desirable to determine DNA amounts in diploid species of Triticineae in order to complete the whole picture of the phylogeny of wheat.

\section{SUMMARY}

1. Comparisons were made of DNA content per nucleus in common wheat, artificially synthesized $6 \mathrm{x}$ wheat, its parental species and three analyzers.

2. DNA content per nucleus in the D genome analyzer was the lowest, B genome had a little lower DNA content than A genome, but the difference between the last two was not significant.

3. Ssp. strangulata had a significantly higher DNA value than var. typica of the same species, Ae. squarrosa.

4. Two strains of synthesized $6 \mathrm{x}$ wheat, ABD No. 1 and ABD No. 13, have nuclear DNA equal to the sum of the DNA contents of their respective parents. Nuclear DNA content of cultivated common wheat (Chinese Spring) is quite the same as that of synthesized 6x wheat, especially ABD No. 13.

5. In three subspecies of $T$. aestivum, vulgare, spelta and macha no significant 
difference was found in DNA content per nucleus.

6. Based on the above facts, the following conclusion may be reasonably drawn as far as wheat and its relatives are concerned:

a) Appreciable changes of DNA content might have resulted from chromosome aberrations accumulated in the course of genome differentiation of a common primitive genome at the diploid level.

b) The three different genomes, once established, have been appreciably stable and kept the amount of DNA constant either in diploid or polyploid condition.

\section{ACKNOWLEDGMENTS}

The authors wish to express their sincere thanks to Dr. I. Hirayoshi, Gifu University for his kind guidance and encouragement throughout the present investigation. The authors' thanks are also due to Dr. F. A. Lilienfeld for her critical reading of the manuscript and valuable suggestions.

\section{LITERATURE CITED}

Bhaskaran, S., and M.S. Swaminathan, 1960 Metaphase chromosome length and DNA content in relation to polyploidy in Triticum species. Exptl. Cell Res. 20: 598-599.

Katayama, T., 1967 Relative amounts of deoxyribonucleic acid (DNA) per nucleus of diploid species in Oryza. Japan. J. Breed. 17: 177-181.

Kihara, H., 1944 Die Entdeckung des DD-Analysators beim Weizen. Agr. Hort. Japan 19: 889-890.

McFadden, E.S., and E.R. Sears, 1944 The artificial synthesis of Triticum spelta. Genetics 30: 14.

McFadden, E.S., and E.R. Sears, 1946 The origin of Triticum spelta and its free threshing hexaploid relatives. J. Heredity 37: 107-116.

Mendelsohn, M.D., 1958 The two-wavelength method of microspectrophotometry. II. A set of tables to facilitate the calculations. J. Biophysic. Biochem. Cytol. 4: 415-424.

Nishikawa, K., and Y. Furuta, 1968 Comparision of DNA content per nucleus between Japanese and U.S. varieties of common wheat. Japan. J. Breed. 18: 94-95.

Pai, R. A., M. D. Upadhya, S. Bhaskaran, and M.S. Swaminathan, 1961 Chromosome diminution and evolution of polyploid species in Triticum. Chromosoma 12: 398-409.

Rees, H., 1963 Deoxyribonucleic acid and the ancestry of wheat. Nature 193: 108-109.

Rees, H., and M. R. Walters, 1965 Nuclear DNA and the evolution of wheat. Heredity 20: 73-82.

Rees, H., and G. H. Jones, 1967 Chromosome evolution in Lolium. Heredity 22: 1-18.

Riley, R., J. Unrau, and V. Chapman, 1958 Evidence on the origin of the B genome of wheat. J. Heredity 49: 91-98.

Rothfels, K., E. Sexsmith, M. Heimburger, and M. O. Krause, 1966 Chromosome size and DNA content of species of Anemone L. and relative genera (Ranunculaceae). Chromosoma 20: 54-74.

Sarker, P., and G. L. Stebbins, 1956 Morphological evidence concerning the origin of the B genome in wheat. Am. J. Botany 43: 297-304.

Sibatani, A., and H. Naora, 1952 Enhancement of color intensity in the histochemical Feulgen reaction. Experimentia 8: 268-269.

Southern, D.I., 1967 Species relationships in the genus Tulipa. Chromosoma 23: 80-94.

Upadhya, M. D., and M. S. Swaminathan, 1965 Deoxyribonucleic acid and the ancestry of wheat. Nature 200: 713-714. 